Int. J. Dev. Biol. 49: 675-687 (2005)

doi: $10.1387 /$ ijdb.041926lh

\title{
The highs and lows of plant life: temperature and light interactions in development
}

\author{
LAURA HEGGIE ${ }^{1}$ and KAREN J. HALLIDAY*,2 \\ ${ }^{1}$ School of Biological Sciences, University of Bristol, U.K. and ${ }^{2}$ The School of Biological Sciences, University of Edinburgh, Scotland, UK.
}

\begin{abstract}
Plants must constantly respond to changes in the environment whilst maintaining developmental and growth processes if they are to survive into the next generation. A complex network of signals from temperature and light must correctly converge to achieve successful development, through vegetative to reproductive growth. Temperature can be thought of as an environmental factor that provides both 'inductive' and 'maintenance' signals in development. It can stimulate developmental processes such as seed dormancy release, germination and vernalization. However, when temperature is not regarded as inductive, an accommodating network of genes work in concert to ensure growth responses occur regardless of fluctuating microclimate conditions. Many of the temperature-regulated developmental pathways are intimately linked with light signaling. For example, light-temperature interactions are major determinants in the timing of reproductive development. Indeed, the ability to process and react to complex environmental cues is crucial for both normal and adaptive development in a changing environment. These responses are frequently mediated by manipulating the phytohormone network, which serves as a powerful, yet adaptable controller of development. This paper illustrates the influential role temperature perception plays throughout plant development and the close interaction between temperature, light and hormone signaling.
\end{abstract}

KEY WORDS: temperature, light, hormone, development, flowering

\section{Introduction}

Plants are sessile organisms that have to readily alter their development and growth responses to survive an ever-changing environment. This involves the correct amalgamation of multiple external signals including temperature and light, in all facets of development, from germination to flowering. Temperature is an environmental factor that has a considerable influence throughout the plant's developmental program. It plays a major role in controling the degree of seed dormancy (Koornneef et al., 2002). In many species a period of after-ripening, when dry seeds are exposed to higher summer temperatures, or a period of dark stratification, when hydrated seeds are exposed to a period of low temperature, is required for germination (Steadman, 2004; Ali-Rachedi et al., 2004). Elevated ambient temperatures enhance elongation growth in Arabidopsis hypocotyls and rosette internodes in responsive vegetative tissue (Gray et al., 1998; Mazzella et al., 2000; Halliday and Whitelam, 2003). Furthermore, in some species, long cool winter periods, are required to enable flowering (Henderson and Dean, 2004). This inductive process, called vernalization, is a strategy that ensures flowering only occurs in the more desirable spring or summer climate. However, plant morphology is also controlled by more complex temperature signals. Growth and development can be shaped quite dramatically by alternating day and night temperatures. Indeed, this is exploited commercially to regulate and standardize the growth habit and flowering time of many ornamental and greenhouse crop plants (Myster and Moe, 1995). Many of the temperature-controlled responses are mediated via the manipulation of endogenous plant hormone levels and/ or signal transduction. For example, gibberellic acid (GA) and abscisic acid (ABA) levels have been shown to be important factors in the regulation of seed dormancy (Koornneef et al., 2002). Both auxin and GA have been shown to have central roles in temperature-controlled elongation responses. Auxin levels increase as ambient temperature rises, therefore, auxin-mediated effects on elongation growth are highly temperature-dependent (Gray et al., 1998). Furthermore, GA biosythesis and signaling have been shown to be altered in plants exposed to differing day time and

Abbreviations used in this paper: ABA, abscisic acid; DIF, difference between day and night temperatures; DT, day temperature; GA, gibberellic acid; NT, night temperature.

\footnotetext{
*Address correspondence to: Dr. Karen J. Halliday. The School of Biological Sciences, University of Edinburgh, King's Buildings, Mayfield Road, Edinburgh, EH9 3JR, Scotland, UK. Fax: +44-117-925-7374. e-mail: karen.halliday@ed.ac.uk
} 
night temperatures (Myster and Moe, 1995; Grindal et al., 1998a; 1998b). This has a marked impact on plant stature as adjustment of this pathway can have considerable affects on stem elongation.

The pathways controlled by environmental signals such as temperature cannot be considered in isolation. Each response draws upon integrated signals and pathways, many of which are regulated by other external cues such as light. Indeed, light is intimately linked with plant development and this is reflected by the number of photoreceptors found in higher plants. In the model plant Arabidopsis thaliana there are at least four families of light receptors: the red $(R)$ and far-red (FR) light absorbing phytochromes and the blue $(\mathrm{B})$ light absorbing cryptochromes, phototropins and ZTL-like photoreceptors (Schultz etal., 2001; Imaizumi etal., 2003; Lin and Shalitin, 2003; Franklin and Whitelam, 2004; Somers et al., 2004). The phytochromes are the largest of these photoreceptor families comprising five isoforms, phyA-phyE, and they exert extensive control on photomorphogenesis (Mathews and Sharrock, 1997). They are unique amongst photoreceptors as they exists in two forms, $\operatorname{Pr}$ (R light absorbing) and $\mathrm{Pfr}$ (FR light absorbing) which are photoreversible. When exposed to red light, Pr undergoes a photochemical conversion to the biologically active Pfr form. However, the resulting physiological response can be negated if Pfr is photoreversed to the inactive Pr form following exposure to FR light. This property means the phytochromes are extraordinarily sensitive to the changes in the relative proportions of $R$ and FR in the surrounding light environment. However, sensitivity is also achieved by manipulation of phytochrome levels (Sharrock and Clack, 2002). phyA is known to mediate responses to light in the FR range of the electromagnetic spectrum, operating in the very low fluence and high irradiance response modes (Franklin and Whitelam, 2004). It accumulates to high levels in imbibed seeds and darkgrown seedlings which results in their exquisite sensitivity to light triggering germination and de-etiolation.

phyA itself is light regulated: upon exposure to light phyA is degraded, though levels rise again following a period of darkness (Sharrock and Clack, 2002). This means that phyA is ideally placed to act as a photoperiodic light receptor. Light-lability is also a characteristic of cryptochrome 2 (cry2); indeed, both these photoreceptors have been shown to participate in the regulation of photoperiodic flowering (Lin et al., 1998; Yanovsky and Kay, 2002; Valverde et al., 2004).

phyB mediates red light responses in a low fluence response mode and is the principle photoreceptor involved in initiating the shade avoidance syndrome of responses (Figure 1) to R:FR ratio light generated by neighboring plants (Halliday etal., 1994; Whitelam et al., 1998; Devlin et al., 2003). Like phyA, phyB induces germination, seedling de-etiolation and controls flowering, but plays a more extensive role in the regulation of elongation growth in the adult plant. The remaining phytochromes have roles that overlap with phyB function, for example, both phyD and phyE are involved the perception of low R:FR ratio light and have roles in the shade avoidance response (Devlin etal., 1998; 1999). The cryptochromes also contribute to de-etiolation in response to $B$ light. Indeed, this is a process that is regulated collectively by the R/FR and $B$ light receptors under white light conditions (Lin et al., 1998; Mazzella et al., 2001). The array of light signals controlling development cannot be separated from temperature responses and hormone mediation (Blázquez, etal., 2003; Halliday etal., 2003; Halliday and Whitelam, 2003; Halliday and Fankhauser, 2003; Swarup et al., 2003). This review examines the integration of these pathways in the control of a range of developmental processes including dormancy release and germination, elongation and flowering responses.

\section{Vegetative development}

\section{Dormancy release and germination}

Seed dormancy is an adaptation that prevents premature germination in environments that are subject to seasonal changes in growth conditions. This characteristic which is controlled by light, temperature and duration of seed storage (after ripening), ensures the availability of a seed stock that is receptive for germination at the appropriate time of year (Koornneef et al., 2002). As germination requirements depend upon prevailing microclimate conditions this attribute is highly variable between species and accessions. Furthermore, the requirement for interplay between environmental signals and endogenous developmental processes means that many genes are involved in the control of this response. Indeed, quantitative trait analysis has demonstrated this for several species including Arabidopsis, barley, rice and wheat (Kato et al., 2001; Alonso-Blanco, et al., 2003; Clerkx et al., 2004; Prada et al., 2004; Veasey et al., 2004). For many plants, seed dormancy can only be either broken by a long period of after-ripening or by stratification, where imbibed seeds are exposed to low-temperatures for a few days (Froud-Williams et al., 1984). Several laboratories have observed that optimal conditions for after-ripening treatment are long periods (months) of relatively mild ambient temperatures (e.g. Steadman, 2002; Ali-Rachedi et al., 2004).

The hormone-balance theory put forward by Wareing in 1971, proposed that simultaneous expression of GA and ABA were required to promote and inhibit germination, respectively. Subsequent studies, particularly molecular, genetic and physiological analysis of Arabidopsis have revealed prominent roles for these hormones in the control of seed dormancy, though other hormones have also been shown contribute to this complex response. ABAdeficient Arabidopsis mutants aba2 and aba3 have reduced seed dormancy whilst $A B A$-insensitive (abi) alleles and enhanced response to $A B A$ (era) mutants also have altered seed germination phenotypes (Koornneef etal., 1984; Finkelstein, 1994; Cutler etal., 1996; Leon-Kloosterziel et al., 1996; Finkelstein and Lynch, 2000; Finkelstein et al., 1998; López-Molina and Chua, 2000; LópezMolina et al., 2001; Parcy et al., 1994). In common with other studies, Ali-Rachedi and co-workers (2004) demonstrated a relationship between temperature-induced dormancy release and reduced $\mathrm{ABA}$ levels in the Arabidopsis Cape Verde Island (Cvi) accession, which has a high propensity for dormancy. Although ABA appears to play a central role, the control of germination appears to require interaction between several hormone pathways, a reflection, perhaps of the multiple levels of control in this important response. This occurs, at least partly via the modification of or events downstream of $A B / 1$. The $A B / 1$ gene encodes a serine-threonine phosphatase that acts to modify ABA action (Wu et al., 2003). Recently, a constitutive triple response 1 (ctr1) allele was identified as an enhancer and an ethylene insensitive 2 (ein2) allele as a repressor of the abi1-1 mutant providing evidence for cross-talk between the ethylene and ABA pathways (Beaudoin et al., 2000). The CTR1 gene encodes a RAF-like serine-threonine kinase that negatively regulates downstream components of the ethylene pathway, including EIN2 (Guo and Ecker, 2004). Analysis 
of ABA-induced germination in the abi1-1 ctr1-10 and abi1-1 ein245 double mutants suggested that ethylene signaling regulates dormancy by counteracting the effects of ABA (Beaudoin et al., 2000). Interplay between ABA and ethylene is further supported by the finding that the ethylene receptor mutant etr $1-1$ is hypersensitive to $A B A$.

The requirement for GAs to promote germination is evident from several observations. Strong alleles of GA biosynthesis genes in Arabidopsis, such as ga 1-3 and ga2-1, fail to germinate and GA application can overcome germination constraints in species that require after-ripening (Koornneef and Van der Veen, 1980; Metzger, 1983; Grappin et al., 2000). GA biosynthesis inhibitors, such as paclobutrazol, have been shown to severely reduce germination, suggesting de novo biosynthesis of GA is necessary for germination (Koornneef and Van der Veen, 1980; Steinbach, 1997). GAs are directly implicated in seed stratification, where the exposure of seed to low temperatures, typically in the $0-5^{\circ} \mathrm{C}$ range, promotes germination. In this process increases in bioactive GAs have been reported in several species (Yamaguchi and Kamiya, 2001). Cold has also been shown to enhance sensitivity to GAs, suggesting that low temperature may act partly by modifying the GA signal (Derkx and Karssen, 1993). Work by Yamauchi et al. (2004) has provided evidence for the temperature manipulation of GA levels in the cold-regulated germination in Arabidopsis. Microarray experiments revealed that $24 \%$ of genes up regulated and $25 \%$ of genes down regulated by a 48 hour cold treatment of $4^{\circ} \mathrm{C}$ were involved in GA signaling. The relatively large proportion of genes in these categories suggested that GA was a major factor controlling germination in response to short periods of cold. More detailed analysis revealed transcript levels of the GA biosynthesis enzymes

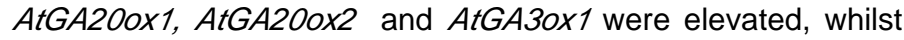
levels of $A t G A 20 \times 2$, an enzyme regulating GA deactivation, were reduced (Yamauchi et al., 2004). This increases levels of GA1 and GA4, key bioactive GAs. Furthermore, analysis of the AtGA3ox1 mutant, ga4-2, revealed a prominent role for $A T G A 3 O X 1$ in this response. Thus, it appears that GA biosynthesis is an important controlling factor in cold accelerated germination.

Experimental evidence has provided links between ABA and GA signaling in the control of germination. In a similar fashion to ein2, the ga1 mutation and the GA-insensitive sleepy 1 (s/y1) mutation were isolated as suppressors of abi1-1 (Steber et al., 1998). This study showed that removal of GA signaling negated the effects of abi1-1 on ABA-mediated inhibition of seed germination. In earlier studies reduced ABA biosynthesis or response has been shown to rescue germination in GA biosynthesis mutants, whilst these mutants suppress the effects of ABA on germination (e.g. Koornneef et al., 1982; Nambara et al., 1992; Léon-Kloosterziel et al., 1996). Thus, ABA and GA appear to have antagonistic roles in the regulation of seed dormancy. REPRESSOR of ga1-3 LIKE 2 (RGAL-2), a DELLA protein has also been shown to negatively regulate germination (Lee at al,. 2002: Tyler et al., 2004). In Arabidopsis the DELLA gene family is small, with five members: GAI (GA-INSENSITIVE), RGA, RGL1-3. Several reports have elegantly demonstrated that GA signaling is controlled by GAmediated degradation of DELLA proteins (Achard et al., 2003; Fu and Harberd, 2003; Sasaki et al., 2003; Cheng et al., 2004). This process appears to be regulated by SLY1, which encodes an F-box protein and component of the SCF-SLY-E3 ubiquitin ligase (McGinnis et al., 2003; Dill et al., 2004). Indeed, SLY1 has been

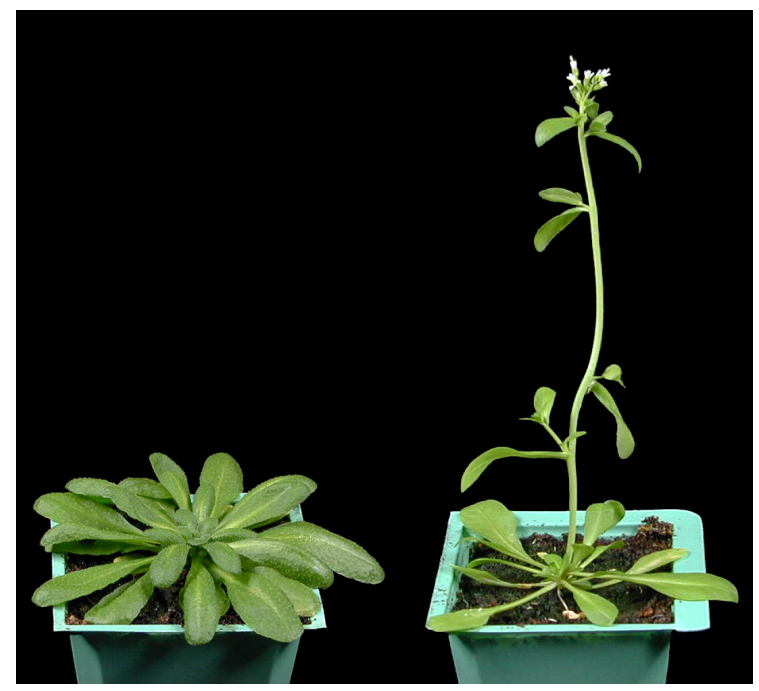

Fig.1. The Shade Avoidance Response. Wild type Arabidopsis (left) and a mutant with deficiencies in phytochrome function, displaying a constitutive shade-avoidance response. Plants were grown in $8 \mathrm{~h}$ photoperiods at $22^{\circ} \mathrm{C}$.

shown to target DELLA proteins for degradation by the proteosome in response to a GA stimulus, suggesting a likely mechanism for GA-control of germination via RGL-2. The manipulation of GAregulation of DELLA protein turnover also appears to be controlled by ethylene and auxin providing the possibility that DELLAs may be a focal point for hormone action in responses like germination (Achard et al., 2003; Fu and Harberd, 2003).

Cold and after-ripening are not the only means of enhancing germination, indeed, light can be very effective in overcoming germination dormancy. Light regulates germination, mainly through the action of the phytochromes. Indeed, this was demonstrated in the now "classical" experiments performed by Borthwick et al., (1952), who demonstrated the R/FR reversibility of germination in lettuce seed. Subsequent work has revealed that the $R / F R$ reversible seed germination in Arabidopsis is primarily mediated by phyB (Shinomura et al., 1994; Shimomura et al., 1998). However, the retention of R/FR-reversible induction of germination in a phy $A$ phy $B$ null mutant suggested roles for other phytochromes in this response (Poppe and Schäfer, 1997). phyA regulates germination to $R$ and FR in the VLFR response mode and FR in the HIR response mode and this response requires phyE action (Shimomura et al., 1994; Casal and Sánchez, 1998; Hennig et al., 2002). It appears that phytochrome action can override the need for temperature signals in the promotion of germination. This is achieved, at least partly, by manipulating GA action. In GA-deficient seedlings $R$ light was shown to enhance $G A$-induced germination, suggesting that phytochrome may moderate sensitivity to GA (Hilhorst \& Karssen, 1988; Yang et al., 1995). However, phytochromes also control GA biosynthesis, as Derkx and Karssen (1993) demonstrated that GA4 concentration in seeds is higher in the light than in the dark, and Yamaguchi et al. (1998) showed that phytochromes positively regulate transcription of the GA biosynthesis genes AtGA3ox1 and AtGA3ox2. While AtGA30x2 mRNA levels appear to be specifically regulated by phyB, AtGA30x1 is subject to control by other phytochromes. The regulation of AtGA30x1 by phytochrome coupled with the requirement for this 
enzyme in cold-promoted GA biosynthesis (see above), suggests that $A t G A 30 \times 1$ may represent a convergence point in temperature- and phytochrome-regulated germination.

\section{Elongation growth}

Continued development and growth of the plant following successful germination is dictated by external environmental factors such as light and temperature and by complex interactions with endogenous phytohormones including GA, ABA, cytokinin, brassinosteriods and auxin. It is auxin, one of the key hormones, that intricately links light and temperature to cell, hypocotyl and stem expansion (Yang et al., 1996; Gray et al., 1998 Thingnaes et al., 2003; Zhao et al., 2003), but precisely how the pathways interact is still poorly understood. Auxin is well known as a potent promoter of cell expansion. This has been shown for stem extension in different species and for hypocotyl elongation in Arabidopsis (Collet et al., 2000; Ross et al., 2001; Thingnaes et al., 2003). The role of auxin in temperature-dependent Arabidopsis hypocotyl elongation was demonstrated by Gray et al. (1998). This work showed that high temperatures could dramatically increase the elongation of light-grown hypocotyls. An elevation in growth temperature from $20^{\circ} \mathrm{C}$ to $29^{\circ} \mathrm{C}$ resulted in a 4- to 5-fold increase in hypocotyl length. Analysis of Arabidopsis auxin response mutants (axr1-12 and tir1-1) and auxin transport mutants (tir3-1) was performed to determine whether this high temperature effect was, in fact, dependent on auxin (Nemhauser et al., 2004). The enhanced elongation observed in wild type seedlings exposed to the higher temperature was completely absent in the axr1-12 mutant and attenuated in the tir1-1 and tir3-1 mutants. Furthermore, temperature-induced elongation growth was shown to be accompanied by elevations in endogenous IAA concentration, suggesting that ambient temperature is an important factor in the regulation of auxin-mediated hypocotyl elongation (Gray et al., 1998; Zhao et al., 2003).

The results described above were determined in light-grown seedlings. But how does light itself interact with temperature and hormones in the tight control of elongation and expansion in plant development? Changes in light quality in the surrounding environment can signal the presence of neighboring plants and potential competition. This light quality change is due to an enrichment of light at the longer FR wavelengths following the absorption of shorter wavelength light by chlorophyll in green tissue. The resulting reduction in R:FR ratio causes bias towards formation of the inactive Pr form of phytochrome in nearby plants and a concomitant reduction in phytochrome-mediate responses. This leads to enhanced elongation growth and accelerated transition to flowering, features of the shade avoidance syndrome of responses (Figure 1; Whitelam and Devlin, 1997). From physiological analysis of Arabidopsis phytochrome null mutants, it is clear that phyB is the principal photoreceptor involved in R:FR ratio signal perception. When compared with wild-type plants, phy $B$ mutants are elongated and early flowering and display attenuated responses to low R:FR ratio (Reed et al., 1993; Halliday et al., 1994; Whitelam etal.,1998). However, analysis of mutants deficient in phytochromes in addition to phyB has revealed roles for phyD and phyE in the shade avoidance response (Devlin et al., 1998; 1999). Several studies illustrate this response is employed as a reactive growth strategy in a range of species. For example, species such as Senecio vulgaris (groundsel) and Chenopodium album (fat hen), have particularly strong shade avoidance strategies and exhibit striking stem extension rates in response to low $R$ :FR ratio light (Smith, 1994). In these species a response to the inductive stimulus was observed within minutes. Other work has uncovered a link between this aspect of the shade avoidance response and temperature in the annual weed Abutilon theophrasti (velvet-leaf) (Weinig, 2000). This study demonstrated that temperature has a major impact on elongation responses to low $\mathrm{R}: \mathrm{FR}$ ratio light in this species. Indeed, a combination of higher temperatures and low $\mathrm{R}: \mathrm{FR}$ ratio were most effective at altering hypocotyl elongation, suggesting that temperature and light may be acting synergistically in this response (Weinig, 2000). This appears to differ from the situation in Arabidopsis, where the impact of temperature on hypocotyl elongation is only slightly altered in phy $A$, phy $B$ and cry 1 mutants or plants carrying combinations of these mutations (Mazzella et al., 2000). However, light appears to have a repressive effect on internode elongation stimulated by elevated temperature during vegetative development (Halliday and Whitelam, 2003; Mazzella et al., 2000). This response appears to be important for the maintenance of the rosette habit of Arabidopsis when ambient temperature increases. In species which form a compact rosette, internode elongation is almost entirely arrested during normal development. However, the sequential removal of photoreceptors revealed roles for both the phytochromes and cryptochromes in this response. When kept at $20^{\circ} \mathrm{C}$ or at alternate $20 / 30^{\circ} \mathrm{C}(15 / 9 \mathrm{~h})$ wild type plants grew with compact rosettes. In contrast the phy $B$, phy $A$ phyB, phyB cry1, phyA phyB cry1 mutants displayed increasing degrees of internode elongation (Mazzella etal., 2000). A similar situation was observed for the phyA phyB phyE mutant which exhibited a pronounced internode phenotype when grown at $21^{\circ} \mathrm{C}$ (Halliday and Whitelam, 2003). These two studies suggest a hierarchy of photoreceptor action in the suppression of internode elongation, with phyB playing the most prominent role. These observed differences in internode elongation, however, were temperature-specific. When grown at cooler temperatures even the most severe photoreceptor mutants (phyA phyB phyE and phyA phy $B$ cry1) showed no signs of internode elongation. So, for this response it appears that the phytochromes and cryptochromes play a role in suppressing elongation induced by elevated ambient temperature. In this instance the light receptor action appears to be important for maintaining the rosette habit in the natural environment which is subject to changes in ambient temperature.

There are many reports of links between phytochrome and auxin providing the possibility that the reported temperatureregulation of phytochrome-controlled elongation is mediated, at least in part by auxin action. Early work by Briggs (1963) showed that $R$ light could reduce levels of auxin in corn and oat coleoptiles, indicating a role for phytochromes in regulating auxin levels. Later, Sherwin and Furuya (1973) demonstrated a R/FR reversible effect on auxin transport in rice coleoptiles, suggesting a role for phytochromes in polar auxin transport. In both tomato and Arabidopsis inhibition of hypocotyl elongation by the auxin transport inhibitor NPA was shown to be light dependent (Jensen et al., 1998; Kraepiel etal., 2001). Furthermore, recent work has shown that low R:FR ratio controls the expression of the auxin efflux carriers $P$ IN3 and PIN7, lending support to this notion (Devlin et al., 2003).

The relationship between light and auxin is very complex extending way beyond the regulation of auxin transport. Light appears to regulate a subset of the rapid auxin response genes 
AuX/IAA, SAUR and GH3 (Abel et al., 1995; Gil and Green, 1997; Tanaka et al., 2002). Indeed, recent DNA array analysis has demonstrated that members of these gene families are regulated by phyA and/or phyB (Tepperman et al., 2001; Devlin et al., 2003). This indicates that light, at least partly via phytochrome action, can control transcription of genes that are also regulated by auxin. Conversely, auxin has been shown to alter the expression of a range of light-regulated genes confirming the close association of light and auxin signaling (e.g. Goda et al., 2004; Gil et al., 2001). Provisional insights into how these pathways are interlocked have come to light recently. LONG HYPOCOTYL 5 (HY5), a bZIP transcription factor, is a central light signaling component which acts downstream of the phytochromes and cryptochromes to regulate photomorphogenesis (Koornneef et al., 1980). HY5 has been shown to regulate transcription by binding to the core G-Box sequence CCACGTG (Ang et al., 1998; Chattopadhyay et al., 1998). This binding site is contained within the promoters of $S L R$ / IAA14 / IAA28 and AXR2/IAA7, genes with reduced expression levels in hy5 mutants (Cluis et al., 2004). Thus, it appears that HY5 may regulate these genes directly providing a molecular link between light and auxin signaling. There is also preliminary evidence that phyA interacts with and phosphorylates Aux/IAA proteins, whilst auxin directly targets them for degradation via action of the SCFTIR1 ubiquitin ligase complex (Colon-Carmona et al., 2000; Kepinski and Leyser, 2004). Collectively, these observations suggest multiple levels of control for Aux/IAAs by light and auxin.

\section{Diurnal temperature effects}

Stem and internode elongation and uniformity are important characteristics in many horticultural and crops plants. Particularly in the horticultural industry, plant morphology is routinely manipulated by altering day length (photoperiod) and temperature of the growth conditions. Plant development can also be influenced by the topical application of hormones, for example, GA, is known to control stem elongation and is often applied to control crop morphology (Grindal et al., 1998a). However, as chemical applications are becoming increasingly less acceptable for use in a commercial environment, thermoperiodic manipulation, i.e. the alteration of day and night temperatures, represents the more acceptable method of regulating plant growth (Myster and Moe, 1995). In many plant species, there is a strong positive correlation between internode length and DIF (the difference between day temperature (DT) and night temperature (NT)). Generally, internode length will increase when DT is warmer than NT (positive DIF) compared to negative DIF (when NT is warmer than DT). For example, this is the case for fuchsia (Maasand van Hattum, 1998), chrysanthemum (Carvalho et al., 2002) and Arabidopsis (Thingnaes et al., 2003). However, the cellular physiology and molecular mechanisms that control thermoperiodic regulation of elongation are still poorly understood. Studies have shown that internode elongation is increased by both cell number and cell length in Campanula isophylla (Strøm and Moe, 1997) and Arabidopsis (Thingnaes et al., 2003). This appears to be controlled, at least to some extent, by GA acting through a thermoperiodic pathway. Grindal and coworkers (1998b) used a series of dwarf pea mutants, with aberrant GA biosynthesis or signaling, to study the relationship between GA1 and DIF-regulated stem elongation. This work demonstrated that stem elongation was dramatically affected by differing day and night time temperatures. For example, wild type pea plants had approximately $50 \%$ shorter internodes when grown under negative compared to positive DIF. The enhanced inhibition of internode elongation correlated with a marked reduction in GA1 levels in these seedlings suggesting that regulation of GA biosynthesis is a major control point for this response. Further analysis showed that pea plants dwarfed by paclobutrazol had a higher rate of $2 \beta$ hydroxylation of GA1, leading to lower levels of endogenous GA1 and shorter stems and internodes under negative DIF (Grindal, 1998a). Together these results indicate that, for pea at least, thermoperiodic responses are mediated by changes in the endogenous levels of GA1, via GA biosynthetic and inactivation steps. However, these do not appear to be the only mechanisms at work in this response as differences in sensitivity to GA can also account for some of the thermoperiodic effects on stem elongation (Weller et al., 1994).

In other species thermoperiodic control of elongation growth is controlled by alternative mechanisms to that observed in pea. In begonia, although stem and internode elongation increases as the DIF increases from negative values to zero, there seems to be no clear relationship between internode elongation and levels of endogenous GAs (Myster et al., 1997). Thingnaes and co-workers (2003) found that temperature treatments in Arabidopsis did not affect levels of bioactive GAs in stem tissue. Although, the possibility of differential regulation of GA in specific tissue types could not be ruled out in this study these results suggest that other phytohormones in addition to gibberellin may be responsible for stem elongation in day and night responses. Auxin has also been shown to play a role in temperature-regulated elongation (see above). Furthermore, in pea, where DIF has a strong impact on development, auxin has been shown to be influential in controlling internode elongation (Yang et al., 1996). Using mutants with deficiencies in endogenous auxin (lkb) or GA (le) levels, studies have demonstrated that both GA and auxin are required for normal stem elongation (Yang et al., 1996; Ross et al., 2002). Indeed, an association has been demonstrated between GA and auxin levels in many species (Ross et al., 2002). Thus, a degree of cross-talk appears to occur between these two pathways at the level of hormone biosynthesis. However, the relationship between these two hormones is not straightforward as they appear to be involved in different aspects of elongation, for example auxin is proposed to regulate cell elongation, whilst GA contributes mainly to cell division. The finding that the $\angle K B$ is a homologue of the Arabidopsis DIMINUTO/DWARF-1 (DIM/DWF1) brassinosteriod synthesis gene, suggests that brassinosteriods also influence auxin levels in pea (Schultz et al., 2001). Indeed, recent work in Arabidopsis has illustrated a strong interdependency between brassinosteriod and auxin signaling in the targeted regulation of common genes (Nemhauser et al., 2004). It is left to future to provide more detailed insights of the relationship between thermoperiod and the hormone network in the control of vegetative development.

\section{Light quality influence on DIF}

In fuchsia, light quality has a significant impact on DIF-regulated elongation (Maas and van Hattum, 1998). Fuchsia plants exhibit the frequently reported stem increased elongation when grown under positive DIF $v s$ conditions of negative DIF. However, the effects observed in response to positive DIF can be phenocopied when plants are grown in negative DIF, but under orange light. Thus, in fuchsia, light and temperature signals appear to converge 
in the regulation of elongation growth. As the orange light used in this study cut out all components of blue light, the observed lightmediated effects could be attributed to loss of cryptochrome action and/or enhanced or altered phytochrome action (Maas and van Hattum, 1998). It is likely that phyB contributes to this response in fuchsia as it been shown to have a prominent role in the control of hypocotyl and stem elongation in several other species. Indeed, phy $B$ mutants in Arabidopsis, pea (IV) and cucumber (Ih) all have constitutively elongated phenotypes (Reed et al., 1993; Weller, 1994; López-Juez et al., 1995). In pea and cucumber the phyBmediated differences in hypocotyl elongation seem to result from differences in GA responsiveness of endogenous levels and not GA levels per se. However, other studies in pea have demonstrated that light negatively regulates GA1 levels in the shoot tip. The reduction in GA1 is accompanied by a concomitant increase in GA8, the inactive product of GA1 suggesting that light regulates GA1 turnover during de-etiolation (Ait-Ali et al., 1999; Gil and García-Martínez, 2000). Reid and co-workers (2002) demonstrated that this process is controlled by phyA and an as yet unidentified blue light receptor. This is achieved by down-regulating PSGA30X1, a gene that controls the conversion of GA20 to GA1 whilst $P s G A 30 \times 2$ that converts GA1 to GA8 is up-regulated. Thus, it is likely that phy $A$ and phyB manipulate different aspects of GA biosynthesis/signaling to regulate elongation responses that are influenced by alternating DT and NT.

\section{The timing of reproductive development}

\section{Vernalization}

Vernalization is a superb example of how plants have evolved to take advantage of environmental cues. Recent work, mainly in Arabidopsis, has provided some exciting insights into how temperature exerts its control over the timing of reproductive development. Vernalization is a process that requires plants to be exposed to prolonged periods of cold before they acquire the competence to flower (Battey and Tooke, 2002; Henderson and Dean, 2004). This strategy ensures that in temperate climates flowering does not occur during unfavorable winter conditions, but in the more agreeable spring or summer situation. In Arabidopsis a central component in this process is FLOWERING LOCUSC (FLC), a MADS box transcriptional regulator, which suppresses flowering (Michaels and Amasino, 1999). This is achieved by the negative regulation of genes required for the transition to flowering such as FLOWERING LOCUS T, (FT), SUPRESSOR OF OVEREXPRESSION OF CONSTANS 1 (SOC1) and $\angle E A F Y$ (LFY). There are numerous Arabidopsis accessions, some of which are winter annuals, whilst others complete their life cycle before the winter months commence. Variation at the $F R I G I D A$ (FRI) locus has been identified as a major source of natural variation in flowering time and the requirement for vernalization in Arabidopsis (Burn et al., 1993; Clarke and Dean, 1994; Johanson et al., 2000; Lee et al., 1993). Indeed, plants that must undergo vernalization before flowering have an active $F R I G I D A$ (FRI) gene, which enhances FLC expression with the consequential repression of flowering (Michaels and Amasino, 1999; Sheldon et al., 1999). Subsequent exposure to long periods of cold during winter gradually reduces $F L C$ RNA levels relieving the restraint on flowering. However, FRI does not appear to act alone in the regulation of $F L C$. A related gene $F R I G I D A L I K E 1$ (FRL1) is required for FRI regulation of $F L C$, whilst a second gene $F R L 2$ may have a similar role to $F R L 1$ (Michaels et al., 2004).

The vernalization process itself, which requires the suppression of $F L C$ activity followed by maintenance of this suppressed state, has been studied intensely in recent years. This process is controlled by VERNALIZATION INSENSITIVE 3 (VIN3) and the VERNALIZATION genes VRN1 and VRN2 via the epigenetic silencing of $F L C$ (Boss et al., 2004). This mechanism provides the plant with "memory" of vernalization such that flowering can be induced some time after the event. This is important for species that have both a vernalization and a photoperiodic requirement for flowering (Battey and Tooke, 2002). In these species the inductive photoperiod occurs some time (often several months) after the completion of vernalization. Recent work on the key components of this response has provided valuable insights into the epigenetic regulation of $F L C$. The earliest acting gene appears to be VIN3 which encodes a protein with a plant homeodomain and fibronectrin type III repeats (Sung and Amasino, 2004). In vin3 mutants the normal cold repression of $F L C$ expression is not observed, these plants flower very late and are unresponsive to vernalization. VIN3 itself is cold responsive, it is up-regulated in response to prolonged periods of cold, known to be sufficient for vernalization. FLC repression has been shown to occur following the appearance and subsequent accumulation of VIN3 transcript. This appears to be achieved by modifying chromatin at the FLC locus. Indeed, VIN3 has been shown to promote $F L C$ histone deacetylation, a process required to establish $F L C$ silencing. This silent state is then maintained by $V R N 1$ and $V R N 2$, which are both constitutively expressed in Arabidopsis. In vrn1 and vrn2 mutants cold-induced $F L C$ repression occurs, but this repressed state is not sustained as it is in wild type plants (Gendall et al., 2001; Levy et al., 2002). VRN1 encodes a DNA-binding protein, whilst VRN2 encodes a zinc-finger protein with homology to $S U(Z) 12$, a member of the polycomb group complex that maintains silenced chromatin states in Drosophila. Both VRN1 and VRN2 have been shown to have similar roles to $S U(Z) 12$ in the stable repression of $F L C$ in Arabidopsis. This is achieved by VRN1- and VRN2-mediated changes in histone methylation that lead to heterochromatin formation and silencing of the FLC locus (Bastow et al., 2004; Sung and Amasino, 2004). These changes are mitotically stable which means that acquisition of flowering competence induced by vernalization is conserved.

Although FLC is a key player in vernalization, this is not the only pathway controlling this process as flc null mutants are still responsive to vernalization (Michaels and Amasino, 2001). Indeed, there are five FLC homologues in Arabidopsis: MADS AFFECTINGFLOWERING(MAF1-5)(Ratcliffe etal., 2003; Ratcliffe et al., 2001; Scortecci et al., 2001). MAF1 (also known as FLOWERING LOCUS M)-MAF4 appear to act as floral repressors. This gene family also controls aspects of vernalization, though their precise function in this process has not yet been fully explored. Overexpression of either MAF1 or MAF2 renders the plants unresponsive to vernalization, suggesting that these genes may have roles in the vernalization process. Interestingly, this control appears to be independent or downstream of FLC as neither MAF1 nor MAF2 influence FLC mRNA levels (Ratcliffe et al., 2003; Ratcliffe et al., 2001). MAF2 appears to regulate the onset of vernalization. maf2 mutants flower early in response to short cold periods, treatments that coincide with the presence of 
MAF2 transcript in wild type plants (Ratcliffe et al., 2003). This suggests that MAF2 represses vernalization in response to brief periods of cold. Presumably this is a mechanism that allows the distinction between cold snaps and seasonal changes in temperature, ensuring that vernalization only proceeds in response to winter. Roles for MAF1/FLM and MAF3-5 are less clear. Expression of these genes is regulated by prolonged exposure to cold, but these effects are much less marked than that observed for FLC. Future work will no doubt reveal the precise roles of these FLC homologues in the temperature-dependent regulation of flowering. It is of interest that in vin3 mutants the vernalization process is completely blocked. Thus, VIN3 appears to be required for FLCdependent and -independent vernalization suggesting similar mechanisms of control for both pathways (Sung and Amasino, 2004).

The downstream targets for the vernalization pathway include $F T$, SOC1 and $\angle F Y$, genes that promote the switch from the vegetative to the reproductive state. Their respective roles in the FLC-dependent pathway have been established through a multitude of studies. Flowering time genes known to act via the FLCautonomous pathway have been shown to regulate $L F Y:: G U S$ activity (Nilsson et al., 1998). Samach et al., (2000) demonstrated that the flowering time gene FCA controls both FT and SOC1 expression. Elevated SOC1 mRNA abundance has been reported in several genotypes with depleted levels of $F L C$, whilst increased FLC levels repress SOC1 transcription (Hepworth et al., 2002; Michaels and Amasino, 2001). The targeting of these three genes, all potent regulators of flowering, ensures that FLC-mediated inhibition of flowering is extremely effective. Recent work has provided evidence that AGAMOUS-LIKE24 (AGL24), a gene with homology to $S O C 1$, is also a target for the vernalization pathway (Michaels et al., 2003; Yu et al., 2002). However, unlike SOC1, AGL24 is up-regulated by an FLC-independent pathway (Michaels et al., 2003). Although these genes may be regulated through different pathways they appear to positively regulate each other's transcription, suggesting a mechanism for cross talk between these temperature-regulated pathways.

\section{Photoperiodic flowering}

The external light environment is extremely influential in the control of flowering time. Light quality and photoperiod length provide valuable information that impacts directly on the plant's developmental program. Photoperiod provides a powerful flowering signal that ensures reproductive development is synchronized within a species at a favorable time of year. Grafting experiments have shown that the photoperiod signal is perceived in the leaf and transmitted to the shoot apical meristem to trigger flowering (e.g. Zeevaart, 1984). The transmissible substance, called "florigen" has remained elusive, although we are now making progress toward its discovery.

Work in several labs has defined many of the constituent parts and the intricate workings of this complex pathway. Just as $F L C$ is an important focal point in the vernalization/autonomous pathway, CONSTANS (CO), a zinc finger transcription factor, has this role in the photoperiodic pathway (Putterill et al., 1995; Searle and Coupland, 2004). In Arabidopsis, a facultative long day (LD) plant, CO promotes flowering in inductive, LD conditions. Indeed, CO has recently been shown to be expressed in phloem companion cells and to generate the transmissible "florigen" signal (An et al., 2004;
Ayre et al., 2004). Production of the inductive floral signal is achieved, at least in part by the cell-automomous activation of $F T$ (An et al., 2004). This combined with the fact that FT is a relatively small protein $(23 \mathrm{kDa})$ means that it is tempting to speculate that $\mathrm{FT}$ may be a component of the enigmatic florigen (An et al., 2004). However, future work will reveal the precise role of FT in this process. There is evidence for conservation of the photoperiodic control of flowering amongst angiosperms as $C O$ and FT homologues have been identified in several species (Liu et al., 2001; Yano et al., 2000; Kojima et al., 2002; Griffiths et al., 2003). In Arabidopsis, FT is not the only target for $\mathrm{CO}$; SOC1 and $\angle F Y$ are also positively regulated by $\mathrm{CO}$ in the photoperiod pathway. $F T$ and SOC1 appear to be direct targets and $\angle F Y$ an indirect target of CO (Hepworth et al., 2002; Nilsson et al., 1998; Samach et al., 2000).

\section{Photoreceptors set the waveform and amplitude of CO mRNA}

Control of $\mathrm{CO}$ in the photoperiodic pathway is achieved by simultaneous action of photoreceptors and the circadian oscillator. Under LDs the peak of $C O$ expression is broader than under SDs with the highest levels of $C O$ mRNA coinciding with dawn and dusk (Suárez-López et al., 2001). This photoperiodic adjustment of $C O$ mRNA, which results from the coincidence of light and the circadian phase, is important for induction of flowering under LDs (Yanovsky and Kay, 2002). The newly defined photoreceptors ZTL1, FKF1 and LPK2 have been shown to have important roles in this process (Imaizumi et al., 2003; Schultz et al., 2001; Somers et al., 2004). The $\mathrm{fkf1}$ mutant was shown to be late flowering under LDs, whilst over expression of either ZTL1 or LPK2 caused a similar phenotype. ZTL1 negatively regulates $C O$ expression, whereas in $f k f 1$ seedlings the waveform of $C O$ expression observed under SDs is unchanged when plants are grown under LDs. Thus, the ZTL1, FKF1 and LPK2 family appear to represent a class of genes that are intimately involved in the discrimination between day length and differences in $C O$ regulation under LDs and SDs. There is also a role for phyA in this process as a phy $A$ null mutation has been demonstrated to alter the waveform of $C O$ expression and slightly reduce levels of $C O$ mRNA in transgenic plants overexpressing $C O$ (Yanovsky and Kay, 2002). Thus, the adjustment of the $C O$ waveform under LDs appears to result from the concerted action of multiple photoreceptors. This photoperiodic modification of $\mathrm{CO}$ has been shown to be crucial for triggering FT expression and hence the induction of flowering. However, FT regulation is also controlled by posttranscriptional mechanisms that involve the action of additional photoreceptors (see below). One point of interest is whether the mechanisms of photoperiodic control are similar or are evolutionarily distinct in short day (SD) and LD species. Analysis of rice, a SD species, has demonstrated that $H D 1$ and $H d 3 a$ appear to have similar functions to their Arabidopsis orthologues CO and FT, respectively (Kojima et al., 2002). However, in contrast to Arabidopsis, flowering is prevented in LDgrown rice as $H D 1$ acts to negatively regulate $\mathrm{Hd} 3 \mathrm{a}$.

\section{Photoreceptor control of the CO-photoperiodic pathway}

Physiological analysis of mutants lacking cry2, cry1 or phyA has demonstrated roles for each of these photoreceptors in photoperiodic flowering (Johnson et al., 1994; Mockler et al., 1999). Mutations in cry 1 , cry2 or phyA delay flowering under LD conditions and cry2 mutants are completely insensitive to photoperiod sug- 


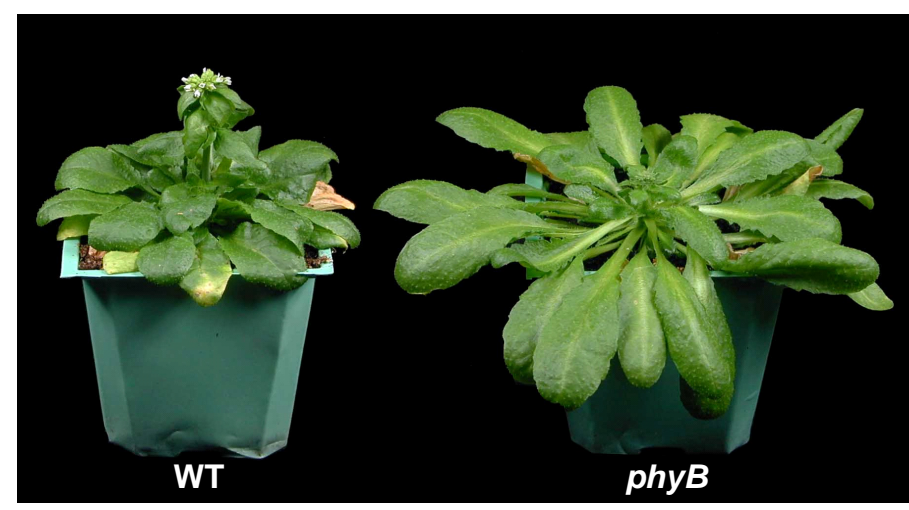

Fig. 2. The early-flowering phyB phenotype is temperature-dependent. When grown at cooler ambient temperatures phyB mutants do not flower earlier than wild type plants. Plants were grown in $8 \mathrm{~h}$ photoperiods at $16^{\circ} \mathrm{C}$.

gesting that each of these photoreceptors have roles in LD-induced flowering. In contrast $p h y B$ null mutants are early flowering and this phenotype is observed in both LDs and SDs (Reed et al., 1994; 1993). Thus, it has been proposed that phyB negatively regulates flowering in a photoperiod independent manner. However, recent work by the Coupland laboratory has shown that action of each of these photoreceptors converges at the photoperiodic gene $\mathrm{CO}$ (Valverde et al., 2004). Indeed, this level of control represents the next layer of regulation in the CO-LD pathway. The cry1, cry2, phyA and phyB photoreceptors regulate $\mathrm{CO}$ protein levels and activity of the pathway as a result. In addition, there are also possible roles for cry 1 and cry2 in the post-translational regulation of $\mathrm{CO}$. In transgenic plants expressing $35 S:: C O$, deficiencies in both cry 1 and cry 2 or phyA alone reduced $C O$ protein levels at dusk in a LD photoperiod. Lower $\mathrm{CO}$ levels were also observed in these lines just after dawn. However, a corresponding transient $\mathrm{CO}$ peak observed in the 35S::CO control was not observed for FT expression in wild type plants and therefore was thought not to be representative of the true situation. In contrast 35S.:CO plants carrying a phy $B$ null mutation had elevated $C O$ levels throughout the LD photoperiod. Thus, it appears that phyB suppresses flowering under LDs by negatively regulating $\mathrm{CO}$ abundance and cry 1 , cry2 and phyA antagonize this action, stabilizing the CO protein which activates $F T$ as dusk approaches. Indeed, antagonistic action for cry2 and phyB has been reported previously for the regulation of flowering under LDs (Mockler et al., 1999). In inductive LD photoperiods it is not known why the promotory pathways predominate over phyB action, however, it may be a result of posttranslational mechanisms or the stimulation of additional enabling pathways. This notion is at least plausible as the large effects the cry1 and cry2 mutations have on FT regulation cannot be fully accounted for by the relatively modest control of $\mathrm{CO}$ protein levels, suggesting that they exert some of their' control of $F T$ by modifying CO activity (Valverde et al., 2004).

\section{phyB control of flowering}

The dramatic early flowering phenotype of the phy $B$ mutant under both LDs and SDs suggests that phyB control of flowering is not restricted to the LD-photoperiodic pathway. Indeed, phyB is the principal photoreceptor controlling the shade avoidance response (Whitelam et al., 1998). This is triggered by FR-enriched light that signals the presence of neighboring plants and potential competition. This initiates a number of physiological responses, which include elongation growth and early flowering (see above). As shade avoidance strategies are implemented independently of photoperiod the mechanism of control should reflect this. Indeed, recent work by the Chory laboratory has identified PHYTOCHROME AND FLOWERING TIME 1 (PFT1), a component required for phyB-regulated flowering that appears to operate in a photoperiodindependent pathway (Cerdan and Chory, 2003). Consistent with its early flowering phenotype, FT levels are high in phyB under LDs and SDs and PFT is required for the enhancement of $F T$ transcript abundance. This process appears to be one that does not involve $\mathrm{CO}$ as $C O$ mRNA did not correlate with flowering time in phy $B$ and pft1. Furthermore, pft1 did not affect flowering time or FT mRNA levels in a $C O$-overexpressing line, suggesting that PFT1 did not have a significant role in the post-translational control of $\mathrm{CO}$. This provides a mechanism for phyB to bypass the floral pathways to control flowering in response to light signals from neighboring plants. The reduced flowering response of $p f t 1$ to end-of-day FR treatments, suggests that PFT1 does indeed play a role in phyBmediate shade-avoidance flowering response.

\section{The interplay of temperature and light in the control of flower- ing time}

Photoreceptor control of flowering time through the photoperiod or light quality pathways has recently been shown to be subject to temperature control. Small changes in temperature can have relatively large effects on flowering time in plants that are deficient in photoreceptor activity (Blázquez et al., 2003; Halliday et al., 2003; Halliday and Whitelam, 2003). Indeed, the frequently reported phy $B$ mutant early flowering phenotype observed at $22-$ $24^{\circ} \mathrm{C}$ is abolished when growth temperatures are lowered to $16^{\circ} \mathrm{C}$ (Figure 2; Halliday et al., 2003). Downstream targets for phyB action have been reported previously: phyB was shown to control flowering by regulating the timing of $\angle F Y$ expression (Hempel etal., 1997; Blázquez, et al., 2003). However, Halliday and co-workers (2003) provided the first evidence that phyB also controlled this process by regulating $F T$. Furthermore, like the phy $B$ mutant flowering response, phyB control of $F T$ was shown to be temperature-dependent. As a first step toward establishing the point of $F T$ control, expression of $C O$ and $F L C$, major regulators of $F T$, were assayed in wild type and phy $B$ null mutants at $16^{\circ} \mathrm{C}$ and $22^{\circ} \mathrm{C}$. The lack of correlation between the $C O$ and $F L C$ mRNA levels with the flowering time suggested that temperature-controlled $F T$ regulation was not achieved via regulation of $F L C$ or $C O$ transcription. This type of analysis also ruled out a major role for another floral integrator gene SOC1. As FLC is controlled at the level of transcription phyB is unlikely to be regulating FT through a FLCdependent mechanism (Henderson and Dean, 2004). However, as phyB has been shown to activate FT partly via $\mathrm{CO}$ and a $\mathrm{CO}-$ independent mechanism requiring PFT1, this provides two possible routes for phyB-control of FT (Cerdan and Chory, 2003; Valverde et al., 2004).

The temperature-conditional phy $B$ early flowering phenotype suggested that phyB was acting to control flowering within a specific temperature range. However, when wild type plants were grown under low R:FR ratio (shade) light at $16^{\circ} \mathrm{C}$ they displayed a classical acceleration of flowering activity (Halliday et al., 2003). This experiment showed that although the phyB-mediated early 
flowering response was perturbed at $16^{\circ} \mathrm{C}$ other phytochromes were capable of fully compensating for the loss of phyB action under the cooler conditions. Further analysis showed that this role was fulfilled, at least partly, by phyE. Under SD conditions phyE null mutants flowered earlier than wild type plants at both $16^{\circ} \mathrm{C}$ and $22^{\circ} \mathrm{C}$ activity (Halliday and Whitelam, 2003). Furthermore, removal of phyE in the phy $A$ phyB phyD triple mutant background, markedly accelerated flowering in plants grown at $16^{\circ} \mathrm{C}$ (Halliday et al., 2003). This was achieved at least in part by regulation of $F T$ as removal of phyE correlated with a rise in $F T$ mRNA levels. Thus, it appears that phyB and phyE both negatively regulate flowering time, however, phyB action predominates at the warmer temperatures, whilst phyE action extends to cooler temperatures.

Interactions between temperature and the photoperiodic pathways controlled by cry 1 , cry2 and phyA have also been reported (Blázquez et al., 2003). The late flowering phenotype of cry2 mutants, observed under LDs at $23^{\circ} \mathrm{C}$, is greatly enhanced when the plants are grown at the cooler temperature of $16^{\circ} \mathrm{C}$, suggesting that cry2 signaling is more prominent at cooler temperatures. Ambient temperature appears to be even more important for cry 1 action as the effect of the cry 1 mutation on flowering is not evident at $23^{\circ} \mathrm{C}$, but clearly visible at $16^{\circ} \mathrm{C}$. These data demonstrate that cry1- and cry2-promotion of flowering in LDs is temperaturedependent and that these two blue light receptors operate over different temperature ranges. phyA is also known to participate in the LD control of flowering (see above), so it was possible that phyA also played a role in this temperature control of this pathway. Removal of phyA in addition to cry2 substantially delayed flowering in plants grown at the warmer temperature, suggesting an interaction between phy $A$ and $c r y 2$ at $23^{\circ} \mathrm{C}$. As, phy A cry 2 plants grown at $23^{\circ} \mathrm{C}$ flowered at similar time as the $c r y 2$ monogenic mutant grown at $16^{\circ} \mathrm{C}$, the authors reasoned that the late flowering phenotype of $c r y 2$ at $16^{\circ} \mathrm{C}$ could result from reduced phyA activity at the cooler temperature. Indeed, the lack of a temperature induced response in the phy $A$ mutant provided support for this hypothesis (Blázquez etal., 2003). However, as other reports have demonstrated a wild type response of phy $A$ mutants to temperature change this could mean that the role of phyA in this process may not be straightforward (Halliday et al., 2003; Halliday and Whitelam, 2003). To further elucidate this thermo-sensory flowering pathway Blázquez and co-workers identified two genes: FVE and FCA as potential controllers of the pathway. fve and fca mutants both flowered late, but at identical times, when grown at $23^{\circ} \mathrm{C}$ or $16^{\circ} \mathrm{C}$ suggesting that they were impaired in temperature sensing. If these genes are involved in regulating this thermosensory pathway they do not appear to be acting solely through FLC, as a decrease in temperature had only a modest effect on FLC mRNA levels. In addition, plants carrying the flc mutation were able to mount a response to temperature, indeed, the response was slightly greater than plants with functional FLC suggesting a small role for FLC in this response. To further explore the effects of temperature on the photoperiodic pathway the expression of $C O$ and the floral integrator genes FT, SOC1 and $\angle F Y$ were examined at $23^{\circ} \mathrm{C}$ and $16^{\circ} \mathrm{C}$. Although changes in ambient temperature had small effects on $C O$ and SOC1 expression, the major effects were seen in $F T$ mRNA levels. These findings were further supported by the analysis of plants overexpressing FT, SOC1 or CO where FT emerged again as the main target for temperature-control of photoperiodic flowering.
These experiments, however, do not rule out a role for $\mathrm{CO}$ in the control of $F T$ via post-translational mechanisms. Furthermore, the retention of a temperature-induced response in the $\mathrm{ft}$ mutant suggests that other downstream floral integrators are involved in this response.

It is interesting that the temperature-effects controlled by the phyB/phyE and the cry1/cry2/phyA pathways are mediated through FT in a largely FLC-independent manner (Halliday et al., 2003; Blázquez etal., 2003). However, both studies suggested that FT is unlikely to be the only floral integrator regulated by the respective thermo-sensory flowering pathways. Again, in both reports, SOC1 does not appear to play a significant role in this process, leaving $\angle F Y$ as a strong candidate. The possibility that these two temperature-regulated flowering pathways target the same genes is intriguing. In this scenario, there could be a common mechanism through which temperature signals impose control on the light regulated flowering pathways. Future work will establish if this is the case.

The flowering genes $F T, \angle F Y$ and SOC1 are emerging as the points of convergence and hence key integrators of the many floral pathways. $\angle F Y$ is regulated by $C O$ in the photoperiodic pathway and GA (Blazquez and Weigel, 2000; Nilsson et al., 1998; Samach et al., 2000). These two pathways both regulate $\angle F Y$ transcription but via different cis elements in the $\angle F Y$ promoter (Blazquez and Weigel, 2000). LFY, FT and SOC1 are common targets for the photoperiodic and the autonomous pathway (Samach etal., 2000). This is illustrated well in experiments showing reduced FT expression in mutants with deficiencies in $C O$ or enhanced levels of $F L C$ (Kardailsky et al., 1999; Kobayashi et al., 1999; Samach et al., 2000; Suarez-Lopez et al., 2001). Several lines of evidence indicate a central role for SOC1 in the control of flowering in the GA, autonomous/vernalization and photoperiodic pathways. In SDs, the flowering time of GA-biosynthetic and GA-signaling mutants correlates with SOC1 expression levels (Moon et al., 2003). SOC1 transcription is photoperiodically regulated and the soc1 mutation can partially suppress the early flowering of 35S::CO (Onouchi, et al., 2000; Samach, et al., 2000), whilst SOC1 expression correlates with FLC levels (Borner etal., 2000; Lee etal., 2000; Samach et al., 2000). Furthermore, SOC1 transcription has been shown to be regulated by the CO-photoperiodic and FLC-automomous pathway acting through different SOC1 promoter sequences (Hepworth et al., 2002). FLC is thought to bind directly to the CArG box, to repress transcription, whilst $\mathrm{CO}$ activates transcription indirectly via a downstream motif. The current flowering model suggests that $\mathrm{CO}$ will bind and activate SOC1 transcription following FLC repression. Cross-talk clearly occurs at different points in the flowering pathways, for example, genetic analysis has shown that mutations in the photoperiodic and autonomous pathways interact in some circumstances (Koornneef et al., 1998). However, FT, LFY and SOC1 represent major control foci for the multiple flowering pathways. It will be of great interest to establish how temperature imposes its effects on their regulation.

\section{Integration of the thermo-sensory flowering pathways}

In LD photoperiods a fall in temperature may signal unfavorable conditions, or perhaps the early onset of winter. Under such conditions both cry 1 and cry 2 action appear to be enhanced, which may be necessary to counteract the slower growth that occurs under cooler conditions. phyB is more active under warmer conditions, the converse of cry 1 and cry2. However, its activity tempera- 
ture range does overlap with cry2, suggesting the antagonistic actions reported for phy $B$ and cry2 are temperature-dependent (Mockler et al., 1999; Valverde et al., 2004). Like phyB, phyE acts as a repressor of flowering, however, it acts over a broader temperature band than phyB (Halliday et al., 2003; Halliday and Whitelam, 2003). The collective action of phyB and phyE ensure that a robust shade-avoidance flowering response is initiated under a wide ambient temperature range. One can envisage that these "redundant" actions of individual photoreceptors ensure that responsiveness to potential neighboring plant competition is maintained through microclimate temperature fluctuations.

\section{Perspectives on temperature-controlled development}

In the real world plants have to respond to changes in the external environment, but they also have to maintain development when conditions fluctuate. These apparently contradictory response modes are put into play throughout the plant's life cycle. Temperature is a good example of an environmental cue that provides both "inductive" and "maintenance" signals. Temperature stimulates developmental events such as germination and vernalization. Under these circumstances developmental pathways and the resulting physiological responses are manipulated by the thermal stimulus. In contrast, temperatures that are not recognized as inductive are accommodated by a flexible network of genes that ensure responses occur regardless of thermal noise. Examples of this are the maintenance of the rosette habit and the shadeavoidance flowering response by photoreceptor action over a temperature range. Such responses, which are characteristic of highly evolved systems, serve to buffer the effects of environment or genotype change on development (Casal et al., 2004; Siegal and Bergman, 2002). The role of individual pathways in these processes is slowly emerging; however, we will need to pan-out to examine larger sections of these interacting networks if we are to understand the underlying properties that govern plant-environmental interactions.

\section{References}

ABEL, S., NGUYEN, M. D. and THEOLOGIS, A. (1995). The ps-iaa4/5-like family of early auxin-inducible messenger RNAs in Arabidopsis thaliana. J. Molec. Biol. 251: 533-549.

ACHARD, P., VRIEZEN, W. H., VAN DER STRAETEN, D. and HARBERD, N. P. (2003). Ethylene regulates Arabidopsis development via the modulation of DELLA protein growth repressor function. Plant Ce// 15: 2816-2825.

AIT-ALI, T., FRANCES, S., WELLER, J. L., REID, J. B., KENDRICK, R. E. and KAMIYA, Y. (1999). Regulation of gibberellin 20-oxidase and gibberellin 3 betahydroxylase transcript accumulation during de-etiolation of pea seedlings. Plant Physiology 121: 783-791.

ALI-RACHEDI, S., BOUINOT, D., WAGNER, M. H., BONNET, M., SOTTA, B., GRAPPIN, P. and JULLIEN, M. (2004). Changes in endogenous abscisic acid levels during dormancy release and maintenance of mature seeds: studies with the Cape Verde Islands ecotype, the dormant model of Arabidopsis thaliana. Planta 219: 479-488.

ALONSO-BLANCO, C., BENTSINK, L., HANHART, C. J., BLANKESTIJN-DE VRIES, $\mathrm{H}$. and KOORNNEEF, M. (2003). Analysis of natural allelic variation at seed dormancy loci of Arabidopsis thaliana. Genetics 164: 711-729.

AMRITPHALE, D., SREENIVASULU, Y. and SINGH, B. (2000). Changes in Membrane Fluidity and Protein Composition during Release of Cucumber Seeds from Dormancy by a Higher Temperature Shift. Annals of Botany 85: 13-18.

AN, H., ROUSSOT, C., SUAREZ-LOPEZ, P., CORBESIER, L., VINCENT, C., PINEIRO, M., HEPWORTH, S., MOURADOV, A., JUSTIN, S., TURNBULL, C. and COUPLAND, G. (2004). CONSTANS acts in the phloem to regulate a systemic signal that induces photoperiodic flowering of Arabidopsis. Development 131: 3615-3626.

ANG, L. H., CHATTOPADHYAY, S., WEI, N., OYAMA, T., OKADA, K., BATSCHAUER, A. and DENG, X. W. (1998). Molecular interaction between COP1 and HY5 defines a regulatory switch for light control of Arabidopsis development. $\mathrm{Mo} / \mathrm{Cell}$ 1: 213-222.

AYRE, B. G. and TURGEON, R. (2004). Graft transmission of a floral stimulant derived from CONSTANS. Plant Physiol. 135: 2271-2278.

BASTOW, R., MYLNE, J. S., LISTER, C., LIPPMAN, Z., MARTIENSSEN, R. A. and DEAN, C. (2004). Vernalization requires epigenetic silencing of $F L C$ by histone methylation. Nature 427: 164-167.

BATTEY, N. H. and TOOKE, F. (2002). Molecular control and variation in the floral transition. Curr. Opin. Plant Biol. 5: 62-68.

BEAUDOIN, N., SERIZET, C., GOSTI, F. and GIRAUDAT, J. (2000). Interactions between abscisic acid and ethylene signaling cascades. Plant Cel/ 12: 11031115.

BLÁZQUEZ, M. A., AHN, J. H. and WEIGEL, D. (2003). A thermosensory pathway controlling flowering time in Arabidopsis thaliana. Nat. Genet. 33: 168-71.

BLÁZQUEZ, M. A. and WEIGEL, D. (2000). Integration of floral inductive signals in Arabidopsis. Nature 404: 889-892.

BORNER, R., KAMPMANN, G., CHANDLER, J., GLEISSNER, R., WISMAN, E., APEL, K. and MELZER, S. (2000). A MADS domain gene involved in the transition to flowering in Arabidopsis. Plant J. 24: 591-599.

BORTHWICK, H. A., HENDRICKS, S. B., PARKER, M. W. and TOOLE, V. K. (1952). A reversible photoreaction controlling seed germination. Proc. Natl. Acad. Sci. USA 38: 662-666.

BOSS, P. K., BASTOW, R. M., MYLNE, J. S. and DEAN, C. (2004). Multiple pathways in the decision to flower: enabling, promoting and resetting. Plant Cell 16 Suppl, S18-31.

BRIGGS, W. R. (1963). Red light, auxin relationships and the phototropic responses of corn and oat coleoptiles. Amer. J. Bot. 50: 196-207.

BURN, J. E., BAGNALL, D. J., METZGER, J. D., DENNIS, E. S. and PEACOCK, W. J. (1993). DNA methylation, vernalization and the initiation of flowering. Proc. Nat/. Acad. Sci. USA 90: 287-291.

CARVALHO, S. M. P., HEUVELINK, E., CASCAIS, R. and VAN KOOTEN, O. (2002). Effect of day and night temperature on internode and stem length in chrysanthemum: is everything explained by DIF? Annals of Botany 90: 111-118.

CASAL, J. J. and SÁNCHEZ, R. A. (1998). Phytochromes and seed germination. Seed Sci. Res. 8: 317-329.

CASAL, J. J., FANKHAUSER, C., COUPLAND, G. and BLÁZQUEZ, M. A. (2004). Signalling for developmental plasticity. Trends Plant Sci. 9: 309-314.

CERDAN, P. D. and CHORY, J. (2003). Regulation of flowering time by light quality. Nature 423: 881-885.

CHATTOPADHYAY, S., ANG, L. H., PUENTE, P., DENG, X. W. and WEI, N. (1998). Arabidopsis bZIP protein HY5 directly interacts with light-responsive promoters in mediating light control of gene expression. Plant Cell 10: 673-683.

CHENG, H., QIN, L., LEE, S., FU, X., RICHARDS, D. E., CAO, D., LUO, D., HARBERD, N. P. and PENG, J. (2004). Gibberellin regulates Arabidopsis floral development via suppression of DELLA protein function. Development 131: 10551064.

CLERKX, E. J., EL-LITHY, M. E., VIERLING, E., RUYS, G. J., BLANKESTIJN-DE VRIES, H., GROOT, S. P., VREUGDENHIL, D. and KOORNNEEF, M. (2004). Analysis of natural allelic variation of Arabidopsis seed germination and seed longevity traits between the accessions Landsberg erecta and Shakdara, using a new recombinant inbred line population. Plant Physiol. 135: 432-443.

CLARKE, J. H. and DEAN, C. (1994). Mapping $F R /$, a locus controlling flowering time and vernalization response in Arabidopsis thaliana. Mol. Gen. Genet. 242: 81-89.

CLUIS, C. P., MOUCHEL, C. F. and HARDTKE, C. S. (2004). The Arabidopsis transcription factor $H Y 5$ integrates light and hormone signaling pathways. Plant J. 38: 332-347.

COCKSHULL, K. E., LANGTON, F. A. and CAVE, C. R. J. (1995). Differential effects of different DIF treatments on chrysanthemum and poinsettia. Acta Horticulturae 378: 15-25.

COLLETT, C. E., HARBERD, N. P. and LEYSER, O. (2000). Hormonal interactions in the control of Arabidopsis hypocotyl elongation. Plant Physiol. 124: 553-562. 
COLON-CARMONA, A., CHEN, D. L., YEH, K. C. and ABEL, S. (2000). Aux/IAA proteins are phosphorylated by phytochrome in vitro. Plant Physiol. 124: 17281738.

CUTLER, S., GHASSEMIAN, M., BONETTA, D., COONEY, S. and MCCOURT,. (1996). A protein farnesyl transferase involved in abscisic acid signal transduction in Arabidopsis. Science 273: 1239-1241.

DERKX, M. P. M. and KARSSEN, C. M. (1993). Variability of light-, gibberellin- and nitrate requirement of Arabidopsis thaliana seeds due to harvest time and condition of dry storage. J. Plant Physiol. 141: 574-582.

DEVLIN, P. F., PATEL, S. R. and WHITELAM, G. C. (1998). Phytochrome E influences internode elongation and flowering time in Arabidopsis. Plant Cell 10: 1479-1487.

DEVLIN, P. F., ROBSON, P. R., PATEL, S. R., GOOSEY, L., SHARROCK, R. A. and WHITELAM, G. C. (1999). Phytochrome D acts in the shade-avoidance syndrome in Arabidopsis by controlling elongation growth and flowering time. Plant Physiol. 119: 909-915.

DEVLIN, P. J., YANOVSKY M. J. and KAY S. A. (2003). A Genomic Analysis of the Shade Avoidance Response in Arabidopsis. Plant Physiol. 133: 1-13.

DILL, A., THOMAS, S. G., HU, J., STEBER, C. M. and SUN, T. P. (2004). The Arabidopsis F-box protein SLEEPY1 targets gibberellin signaling repressors for gibberellin-induced degradation. Plant Cell 16: 1392-1405.

FINKELSTEIN, R. R. (1994). Maternal effects govern variable dominance of two abscisic acid response mutations in Arabidopsis thaliana. Plant Physiol. 105: 1203-1208.

FINKELSTEIN, R. R. and LYNCH, T. J. (2000). Abscisic acid inhibition of radicle emergence but not seedling growth is suppressed by sugars. Plant Physiol. 122: 1179-1186.

FINKELSTEIN, R. R., WANG, M. L., LYNCH, T. J., RAO, S. and GOODMAN, H. M. (1998). The Arabidopsis abscisic acid response locus $A B / 4$ encodes an APETALA 2 domain protein. Plant Cel/ 10: 1043-1054.

FRANKLIN K, A. and WHITELAM, G. C. (2004). Light signals, phytochromes and cross-talk with other environmental cues. J. Exp. Biol. 55: 271-276.

FROUD-WILLIAMS, R., CHANCELLOR, R. J. and DRENNAN, D. S. H. (1984). The effects of seed burial and soil disturbance on emergence and survival of arable weeds in relation to minimal cultivation. J. Appl. Ecology 21: 629-641.

FU, X. and HARBERD, N. P. (2003). Auxin promotes Arabidopsis root growth by modulating gibberellin response. Nature 421: 740-743.

GARCIA-MARTINEZ, J. L. and GIL, J. (2001). Light regulation of gibberellin biosynthesis and mode of action. J. Plant Growth Regul. 20: 354-368.

GENDALL, A. R., LEVY, Y. Y., WILSON, A. and DEAN, C. (2001). The VERNALIZATION 2 gene mediates the epigenetic regulation of vernalization in Arabidopsis. Cell 107: 525-535.

GIL, J. and GARCÍA-MARTÍNEZ J. L. (2000). Light regulation of gibberellin A(1) content and expression of genes coding for GA 20-oxidase and GA $3 \beta$-hydroxylase in etiolated pea seedlings. Physiol. Plant. 180: 223-229.

GIL, P., DEWEY, E., FRIML, J., ZHAO, Y., SNOWDEN, K. C., PUTTERILL, J., PALME, K., ESTELLE, M. and CHORY, J. (2001). BIG: a calossin-like protein required for polar auxin transport in Arabidopsis. Genes Dev. 15: 1985-1997.

GIL, P. and GREEN, P. J. (1997). Regulatory activity exerted by the SAUR-AC1 promoter region in transgenic plants. Plant Mol. Biol. 34: 803-808.

GODA, H., SAWA, S., ASAM,I T., FUJIOKA, S., SHIMADA, Y. and YOSHIDA, S. (2004). Comprehensive comparison of auxin-regulated and brassinosteroidregulated genes in Arabidopsis. Plant Physiol. 134: 1555-1573.

GRAPPIN, P., BOUINOT, D., SOTTA, B., MIGINIAC, E. and JULLIEN, M. (2000). Control of seed dormancy in Nicotiana plumbaginifolia: post-imbibition abscisic acid synthesis imposes dormancy maintenance. Planta 210: 279-285.

GRAY, W. M., OSTIN, A., SANDBERG, G., ROMANO, C. P. and ESTELLE, M. (1998). High temperature promotes auxin-mediated hypocotyl elongation in Arabidopsis. Proc Natl. Acad. Sci. USA 95: 7197-7202.

GRIFFITHS, S., DUNFORD, R. P., COUPLAND, G. and LAURIE, D. A. (2003). The evolution of CONSTANS-like gene families in barley, rice and Arabidopsis. Plant Physiol. 131: 1855-1867.

GRINDAL, G., ERNSTSEN, A., REID, J. B., JUNTTILA, O., LINDGÅRD, B. and MOE, R. (1998a). Endogenous gibberellin A1 levels control thermoperiodic stem elongation in Pisum sativum. Physiologia Plantarum 102: 523-531.
GRINDAL, G., JUNTTILA, O., REID, J. B. and MOE R. (1998b). The response to gibberellin in Pisum sativum grown under alternating day and night temperature. J. Plant Growth Regul. 17: 161-167.

GUO, H. and ECKER, J. R. (2004). The ethylene signaling pathway: new insights. Curr. Opin. Plant Biol. 7: 40-49.

HALLIDAY, K. J. and FANKHAUSER, C. (2003) Phytochrome-hormonal signalling networks. Tansley Review, New Phytol. 157: 449-463.

HALLIDAY, K. J., KOORNNEEF, M. and WHITELAM, G. C. (1994). Phytochrome B and at least one other phytochrome, mediate the accelerated flowering response of Arabidopsis thaliana L. to low red/far-red ratio. Plant Physiol. 104: 1311-1315.

HALLIDAY, K. J., SALTER, M. G., THINGNAES, E. and WHITELAM, G. C. (2003). Phytochrome control of flowering is temperature sensitive and correlates with expression of the floral integrator FT. Plant J. 33: 875-885.

HALLIDAY, K. J. and WHITELAM, G. C. (2003). Changes in photoperiod or temperature alter the functional relationships between phytochromes and reveal roles for phyD and phyE. Plant Physiol. 131: 1913-1920.

HEMPEL, F. D., WEIGEL, D., MANDEL, M. A., DITTA, G., ZAMBRYSKI, P. C., FELDMAN, L. J. and YANOFSKY, M. F. (1997). Floral determination and expression of floral regulatory genes in Arabidopsis. Development 124: 3845-3853.

HENDERSON, I. R. and DEAN, C. (2004). Control of Arabidopsis flowering: the chill before the bloom. Development 131: 3829-3838.

HENNIG, L., STODDART, W. M., DIETERLE, M., WHITELAM, G. C. and SCHAFER, E. (2002). Phytochrome E controls light-induced germination of Arabidopsis. Plant Physiol. 128: 194-200.

HEPWORTH, S. R., VALVERDE, F., RAVENSCROFT, D., MOURADOV, A. and COUPLAND, G. (2002). Antagonistic regulation of flowering-time gene SOC1 by CONSTANS and FLC via separate promoter motifs. EMBO J. 21: 4327-4337.

HILHORST, H. W. M. AND KARSSEN, C. M. (1988). Dual effect of light on the gibberellin- and nitrate-stimulated seed germination of Sisymbrium officinale and Arabidopsis thaliana. Plant Physiol. 86: 591-597.

IMAIZUMI, T., TRAN, H. G., SWARTZ, T. E., BRIGGS, W. R. and KAY, S. A. (2003). FKF1 is essential for photoperiodic-specific light signaling in Arabidopsis. Nature 426: 302-306.

JENSEN, P. J., HANGARTER, R. P. and ESTELLE, M. (1998). Auxin transport is required for hypocotyl elongation in light-grown but not dark-grown Arabidopsis. Plant Physiol. 116: 455-462.

JOHANSON, U., WEST, J., LISTER, C., MICHAELS, S., AMASINO, R. and DEAN, C. (2000). Molecular analysis of $F R I G I D A$, a major determinant of natural variation in Arabidopsis flowering time. Science 290: 344-347.

JOHNSON, E., BRADlEY, M., HARBERD, N. P. and WHITELAM, G. C. (1994). Photoresponses of light-grown phyA mutants of Arabidopsis : phytochrome $A$ is required for the perception of daylength extensions. Plant Physiol. 105: 141-149.

KARDAILSKY, I., SHUKLA, V. K., AHN, J. H., DAGENAIS, N., CHRISTENSEN, S. K., NGUYEN, J. T., CHORY, J., HARRISON, M. J. and WEIGEL, D. (1999). Activation tagging of the floral inducer FT. Science 286: 1962-1965.

KOBAYASHI, Y., KAYA, H., GOTO, K., IWABUCHI, M. and ARAKI, T. (1999). A pair of related genes with antagonistic roles in mediating flowering signals. Science 286: 1960-1962.

KATO, K., W. NAKAMURA, T. TABIKI, H. MIURA AND SAWADA, S. (2001). Detection of loci controlling seed dormancy on group 4 chromosomes of wheat and comparative mapping with rice and barley genomes. Theor. Appl. Genet. 102: 980-985.

KEPINSKI, S AND LEYSER, O. (2004). Auxin-induced SCFTIR1-Aux/IAA interaction involves stable modification of the SCFTIR1 complex. Proc. Natl. Acad. Sci. USA 101: 12381-12386.

KOJIMA, S., TAKAHASHI, Y., KOBAYASHI, Y., MONNA, L., SASAKI, T., ARAKI, T. and YANO, M. (2002). Hd3a, a rice ortholog of the Arabidopsis FT gene, promotes transition to flowering downstream of $\mathrm{Hd} 1$ under short-day conditions. Plant Cell Physiol. 43: 1096-1105.

KOORNNEEF, M., ALONSO-BLANCO, C., BLANKESTIJN-DE VRIES, H., HANHART, C. J. and PEETERS, A. J. (1998). Genetic interactions among late-flowering mutants of Arabidopsis. Genetics 148: 885-892.

KOORNNEEF, M., BENTSINK, L. and HILHORST, H. (2002). Seed dormancy and germination. Curr. Opin. Plant Biol. 5: 33-36.

KOORNNEEF, M., REULING, G. and KARSSEN, C. M. (1984). The isolation and 
characterization of abscisic acid-insensitive mutants of Arabidopsis thaliana. Physiol. Plant 61: 377-383.

KOORNNEEF, M., JORNA, M. L., BRINKHORST-VAN DER SWAN D. L. C. and KARSSEN, C. M. (1982). The isolation and analysis of abscisic acid (ABA)-deficient mutants by selection of induced revertants in non-germinating gibberellin sensitive lines of Arabidopsis thaliana (L.)-Heynh. Theor. Appl. Genl. 61: 385-393.

KOORNNEEF, M., ROLFF, E. and SPRUIT, C. J. P. (1980). Genetic control of lightinhibited hypocotyl elongation in Arabidopsis thaliana (L.). Heynh ZPflanzenphysiol 100S, 147-160.

KOORNNEEF, M. and VAN DER VEEN, J. H. (1980). Induction and analysis of gibberellin-insensitive mutants in Arabidopsis thaliana (L.) Heynh. Theor. Appl. Genet. 58: 257-263.

KRAEPIEL, Y., AGNES, C., THIERY, L., MALDINEY, R., MIGINIAC, E. and DELARUE, M. (2001). The growth of tomato (Lycopersicon esculentum Mill.) hypocotyls in the light and in darkness differentially involves auxin. Plant Sci. 161: 1067-1074.

LEE, H., SUH, S. S., PARK, E., CHO, E., AHN, J. H., KIM, S. G., LEE, J. S., KWON, Y M. and LEE, I. (2000). The AGAMOUS-LIKE 20 MADS domain protein integrates floral inductive pathways in Arabidopsis. Genes Dev. 14: 2366-2376.

LEE, I., BLEECKER, A. and AMASINO, R. (1993). Analysis of naturally occurring late flowering in Arabidopsis thaliana. Mol. Gen. Genet. 237: 171-176.

LEE, S., CHENG, H., KING, K. E., WANG, W., HE, Y., HUSSAIN, A., LO, J., HARBERD, N.P. and PENG, J. (2002). Gibberellin regulates Arabidopsis seed germination via $R G L 2$, a $G A / / R G A$-like gene whose expression is up-regulated following imbibition. Genes Dev. 16: 646-658.

LÉON-KLOOSTERZIEL, K. M., VAN DE BUNT, G. A., ZEEVAART, J. A. and KOORNNEEF, M. (1996). Arabidopsis mutants with a reduced seed dormancy. Plant Physiol. 110: 233-240.

LEVY, Y. Y., MESNAGE, S., MYLNE, J. S., GENDALL, A. R. and DEAN, C. (2002). Multiple roles of Arabidopsis $V R N 1$ in vernalization and flowering time control. Science 297: 243-246.

LIN, C. and SHALITIN, D. (2003). Cryptochrome structure and signal transduction. Annu. Rev. Plant Biol. 54: 469-496.

LIN, C., YANG, H., GUO, H., MOCKLER, T., CHEN, J. and CASHMORE, A. R. (1998) Enhancement of blue-light sensitivity of Arabidopsis seedlings by a blue light receptor cryptochrome 2. Proc. Natl. Acad. Sci. USA 95: 2686-2690.

LINCOLN, C., BRITTON, J. H. and ESTELLE, M. (1990). Growth and development of the axr1 mutants of Arabidopsis. Plant Cell 2: 1071-1080.

LIU, J., YU, J., MCINTOSH, L., KENDE, H. and ZEEVAART, J. A. (2001). Isolation of a CONSTANS ortholog from Pharbitis nil and its role in flowering. Plant Physiol. 125: $1821-1830$.

LÓPEZ-JUEZ, E., KOBAYASHI, M., SAKURAI, A., KAMIYA, Y. and KENDRICK, R. E. (1995). Phytochrome, gibberellins and hypocotyl growth - a study using the cucumber (Cucumis-sativus I) long hypocotyl mutant. Plant Physiol. 107: 131-140.

LÓPEZ-MOLINA, L. and CHUA, N. H. (2000). A null mutation in a bZIP factor confers ABA-insensitivity in Arabidopsis thaliana. Plant Cell Physiol 41: 541-547.

LÓPEZ-MOLINA, L., MONGRAND, S. and CHUA, N. H. (2001). A postgermination developmental arrest checkpoint is mediated by abscisic acid and requires the $A B / 5$ transcription factor in Arabidopsis. Proc. Natl. Acad. Sci. USA 98: 4782-4787.

MAAS, F. M. and VAN HATTUM, J. (1998). Thermomorphogenic and photomorphogenic control of stem elongation in Fuchsia is not mediated by changes in responsiveness to gibberellins. J. Plant Growth Regul. 17: 39-45.

MATHEWS, S. and SHARROCK, R. A. (1997). Phytochrome gene diversity. Plant Cell Env. 20: 666-671.

MAZZELLA, M. A., BERTERO, D. and CASAL, J. J. (2000). Temperature-dependent internode elongation in vegetative plants of Arabidopsis thaliana lacking phytochrome B and cryptochrome 1. Planta 210: 497-501.

MAZZELLA, M. A., CERDAN, P. D., STANELONI, R. J. and CASAL, J. J. (2001). Hierarchical coupling of phytochromes and cryptochromes reconciles stability and light modulation of Arabidopsis development. Development 128: 2291-2299.

MCGINNIS, K. M., THOMAS, S. G., SOULE, J. D., STRADER, L. C., ZALE, J. M., SUN, T. P. and STEBER, C. M. (2003). The Arabidopsis SLEEPY1 gene encodes a putative F-box subunit of an SCF E3 ubiquitin ligase. Plant Cell 15: 1120-1130.

METZGER, J. D. (1983). Promotion of germination of dormant weed seeds by substituted phtalimides and gibberellic acid. Weed Science 31: 285-289.

MICHAELS, S. D. and AMASINO, R. M. (1999). FLOWERING LOCUS C encodes a novel MADS domain protein that acts as a repressor of flowering. Plant Ce//11:949956.

MICHAELS, S. D. and AMASINO, R. M. (2001). Loss of FLOWERING LOCUS C activity eliminates the late-flowering phenotype of $F R / G I D A$ and autonomous pathway mutations but not responsiveness to vernalization. Plant Ce// 13: 935-941.

MICHAELS, S. D., BEZERRA, I. C. and AMASINO, R. M. (2004). FRIGIDA-related genes are required for the winter-annual habit in Arabidopsis. Proc. Natl. Acad. Sci. USA 101: 3281-3285.

MICHAELS, S. D., DITTA, G., GUSTAFSON-BROWN, C., PELAZ, S., YANOFSKY, M. and AMASINO, R. M. (2003). AGL24 acts as a promoter of flowering in Arabidopsis and is positively regulated by vernalization. Plant J. 33: 867-874.

MOCKLER, T. C., GUO, H., YANG, H., DUONG, H. and LIN, C. (1999). Antagonistic actions of Arabidopsis cryptochromes and phytochrome $B$ in the regulation of floral induction. Development 126: 2073-2082.

MOON, J., SUH, S. S., LEE, H., CHOI, K. R., HONG C. B., PAEK, N. C., KIM, S. G. and LEE, I. (2003). The SOC1 MADS-box gene integrates vernalization and gibberellin signals for flowering in Arabidopsis. Plant J. 35: 613-623.

MYSTER, J., ERNSTSEN, A., JUNTTILA, O. and MOE, R. (1997). Thermo- and photoperiodicity and involvement of gibberellins during day and night cycle on elongation growth of Begonia x Hiemalis fotsch. J. Plant Growth Regul. 16: 189196.

MYSTER, J. A. and MOE, R. (1995). Effect of diurnal temperature alternations on plant morphology in some greenhouse crops-a mini review. Scientia Horticulturae 62 : 205-215.

NILSSON, O., LEE, I., BLAZQUEZ, M. A. and WEIGEL, D. (1998). Flowering-time genes modulate the response to $\angle E A F Y$ activity. Genetics 150: 403-410.

NAMBARA, E., SATOSHIN. and MCCOURT, P. (1992). A mutant of Arabidopsis which is defective in seed development and storage protein accumulation is a new abi3 allele. Plant J. 2: 435-441.

NEMHAUSER, J. L., MOCKLER, T. C. and CHORY, J. (2004). Interdependency of brassinosteroid and auxin signaling in Arabidopsis. PLOS Biol. 2: E258, Aug 24.

ONOUCHI, H., IGENO, M. I., PERILLEUX, C., GRAVES, K. and COUPLAND, G. (2000). Mutagenesis of plants overexpressing CONSTANS demonstrates novel interactions among Arabidopsis flowering-time genes. Plant Cell 12: 885-900.

PARCY, F., VALON, C., RAYNAL, M., GAUBIER-COMELLA, P., DELSENY, M. and GIRAUDAT, J. (1994). Regulation of gene expression programs during Arabidopsis seed development: roles of the $A B / 3$ locus and of endogenous abscisic acid. Plant Cell 6: 1567-1582.

POPPE, C. and SCHÄFER, E. (1997). Seed germination of Arabidopsis thaliana phyA/ phy $B$ double mutants is under phytochrome control. Plant Physiol. 114:1487-1492.

PRADA, D., ROMAGOSA, I., ULLRICH, S. E. and MOLINA-CANO, J. L. (2004). A centromeric region on chromosome $6(6 \mathrm{H})$ affects dormancy in an induced mutant in barley. J. Exp. Bot. In-press.

PUTTERILL, J., ROBSON, F., LEE, K., SIMON, R. and COUPLAND, G. (1995). The CONSTANS gene of Arabidopsis promotes flowering and encodes a protein showing similarities to zinc finger transcription factors. Cel/ 80: 847-857.

RATCLIFFE, O. J., KUMIMOTO, R. W., WONG, B. J. and RIECHMANN, J. L. (2003). Analysis of the Arabidopsis MADS AFFECTING FLOWERING gene family: MAF2 prevents vernalization by short periods of cold. Plant Cell 15: 1159-1169.

RATCLIFFE, O. J., NADZAN, G. C., REUBER, T. L. and RIECHMANN, J. L. (2001). Regulation of flowering in Arabidopsis by an FLC homologue. Plant Physiol. 126: 122-132.

REED, J. W., NAGATANI, A., ELICH, T. D., FAGAN, M. and CHORY, J. (1994). Phytochrome $A$ and phytochrome $B$ have overlapping but distinct functions in Arabidopsis development. Plant Physiol. 104: 1139-1149.

REED, J. W., NAGPAL, P., POOLE, D. S., FURUYA, M. and CHORY, J. (1993). Mutations in the gene for the red/far-red light receptor phytochrome $B$ alter cell elongation and physiological responses throughout Arabidopsis development. Plant Cell 5: 147-157.

REID, J. B., BOTWRIGHT, N. A., SMITH, J. J., O'NEILL, D. P. and KERCKHOFFS, L. H. (2002). Control of gibberellin levels and gene expression during de-etiolation in pea. Plant Physiol. 128: 734-741.

ROSS, J. J., O'NEILL, D. P., WOLBANG, C. M., SYMONS, G. M. and REID, J. B. (2001). Auxin-gibberellin interactions and their role in plant growth. J. Plant Growth Regul. 20: 336-353. 
SAMACH, A., ONOUCHI, H., GOLD, S. E., DITTA, G. S., SCHWARZ-SOMMER, Z., YANOFSKY, M. F. and COUPLAND, G. (2000). Distinct roles of CONSTANS target genes in reproductive development of Arabidopsis. Science 288: 1613-1616.

SASAKI, A., ITOH, H., GOMI, K., UEGUCHI-TANAKA, M., ISHIYAMA, K., KOBAYASHI, M., JEONG, D. H., AN, G., KITANO, H., ASHIKARI, M. and MATSUOKA, M. (2003). Accumulation of phosphorylated repressor for gibberellin signaling in an F-box mutant. Science 299: 1896-1898.

SCHULTZ, L., KERCKHOFFS, L,H., KLAHRE, U., YOKOTA, T. and REID, J. B. (2001). Molecular characterization of the brassinosteroid-deficient $/ k b$ mutant in pea. Plant Mol. Biol. 47:491-498.

SCHULTZ, T. F., KIYOSUE, T., YANOVSKY, M., WADA, M. and KAY, S. A. (2001). A role for' $\angle K P 2$ in the circadian clock of Arabidopsis. Plant Cell 13: 2659-2670.

SCORTECCI, K. C., MICHAELS, S. D. and AMASINO, R. M. (2001). Identification of a MADS-box gene, FLOWERING LOCUSM, that represses flowering. Plant J. 26: 229-236.

SEARLE, I. and COUPLAND, G. (2004). Induction of flowering by seasonal changes in photoperiod. EMBO J.23: 1217-1222.

SHARROCK, R. A. and CLACK, T. (2002). Patterns of expression and normalized levels of the five Arabidopsis phytochromes. Plant Physiol. 130: 442-456.

SHELDON, C. C., BURN, J. E., PEREZ, P. P., METZGER, J., EDWARDS, J. A., PEACOCK, W. J. and DENNIS, E. S. (1999). The FLFMADS box gene: a repressor of flowering in Arabidopsis regulated by vernalization and methylation. Plant Cell 11: 445-458.

SHERWIN, J. E. and FURUYA, M. (1973). A red-far red reversible effect on uptake of exogenous indole-acetic acid in etiolated rice coleoptiles. Plant Physiol. 51: 295298.

SHINOMURA, T., HANZAWA, H., SCHAFER, E. and FURUYA, M. (1998). Mode of phytochrome $\mathrm{B}$ action in the photoregulation of seed germination in Arabidopsis thaliana. Plant J. 13: 583-590.

SHINOMURA, T., NAGATANI, A., CHORY, J. and FURUYA, M. (1994). The induction of seed germination in Arabidopsis thaliana is regulated principally by phytochrome B and secondarily by phytochrome A. Plant Physiol. 104: 363-371.

SIEGAL, M. L. and BERGMAN, A. (2002). Waddington's canalization revisited: developmental stability and evolution. Proc. Natt. Acad. Sci. USA 99: 10528-10532.

SMITH, H. (1994). Sensing the light environment: the functions of the phytochrome family. In: Photomorphogenesis in Plants - 2nd Edition. Eds: R. E. Kendrick and G. H. M. Kronenberg. Kluwer Academic Publishers.

SOMERS, D. E., KIM, W. Y. and GENG, R. (2004). The F-box protein ZEITLUPE confers dosage-dependent control on the circadian clock, photomorphogenesis and flowering time. Plant Cell 16: 769-782.

STEADMAN, K. J. (2002). A summary of dormancy in annual ryegrass (Lolium rigidum ) seeds: dry after-ripening versus imbibition in the dark. In 13th Australian weeds conference papers and proceedings (ed. J. H. Spafford, Dodd, J. and Moore J. H.), pp. 468-470. Meredith, Australia: Plant Protection Society of WA.

STEADMAN, K. J. (2004). Dormancy release during hydrated storage in Lolium rigidum seeds is dependent on temperature, light quality and hydration status. J. Exp Bot. 398: 929-937.

STEBER, C. M., COONEY, S. E. and MCCOURT, P. (1998). Isolation of the GAresponse mutant sly1 as a suppressor of ABI1-1 in Arabidopsis thaliana. Genetics 149: 509-521.

STEINBACH, H. S., BENECH-ARNOLD, R. L. and SANCHEZ, R. A. (1997). Hormonal regulation of dormancy in developing Sorghum seeds. Plant Physiol. 113: 149-154.

STRØM, M. and MOE. R. (1997). DIF affects internode and cell extension growth and cell number in Campanula isophylla shoots. Acta Horticulturae 435: 17-24.

SUAREZ-LOPEZ, P., WHEATLEY, K., ROBSON, F., ONOUCHI, H., VALVERDE, F. and COUPLAND, G. (2001). CONSTANS mediates between the circadian clock and the control of flowering in Arabidopsis. Nature 410: 1116-1120.

SUNG, S. and AMASINO, R. M. (2004). Vernalization in Arabidopsis thaliana is mediated by the PHD finger protein VIN3. Nature 427: 159-164.

SWARUP, R., PARRY, G., GRAHAM, N., ALLEN, T. and BENNETT, M. (2002). Auxin cross-talk: integration of signaling pathways to control plant development. Plant Mol. Biol. 49: 411-426.

TANAKA, S., MOCHIZUKI, N. and NAGATANI, A. (2002). Expression of the AtGH3a gene, an Arabidopsis homologue of the soybean $G H 3$ gene, is regulated by phytochrome B. Plant Cell Physiol. 43: 281-289.

TEPPERMAN, J. M., ZHU, T., CHANG, H. S., WANG, X. and QUAIL, P. H. (2001). Multiple transcription-factor genes are early targets of phytochrome A signaling. Proc. Natl. Acad. Sci. USA 98: 9437-9442.

THINGNAES, E., TORRE, S., ERNSTSEN, A. and MOE, R. (2003). Day and night temperature responses in Arabidopsis: effects on gibberellin and auxin content, cell size, morphology and flowering time. Ann. Bot. (Lond) 92: 601-612.

TYLER, L., THOMAS, S. G., HU, J., DILL, A., ALONSO, J. M., ECKER, J. R. and SUN, T. P. (2004). Della proteins and gibberellin-regulated seed germination and floral development in Arabidopsis. Plant Physiol. 135: 1008-1019.

VALVERDE, F., MOURADOV, A., SOPPE, W., RAVENSCROFT, D., SAMACH, A. and COUPLAND, G. (2004). Photoreceptor regulation of CONSTANS protein in photoperiodic flowering. Science 303: 1003-1006.

VEASEY, E. A., KARASAWA, M. G., SANTOS, P. P., ROSA, M. S., MAMANI, E. and OLIVEIRA, G. C. (2004). Variation in the loss of seed dormancy during afterripening of wild and cultivated rice species. Ann. Bot (Lond.) oct 7.

WAREING, P. F. AND SAUNDERS, P. F. (1971). Hormones and dormancy. Ann. Rev. Plant Physiol. 22: 261-288.

WEINIG, C. (2000). Limits to adaptive plasticity: temperature and photoperiod influence shade-avoidance responses. Am. J. Bot. 87: 1660-1668.

WELLER, J. L., ROSS, J. J. and REID, J. B. (1994). Gibberellins and phytochrome regulation of stem elongation in pea. Planta 192: 489-496.

WHITELAM, G. C. and DEVLIN, P. F. (1997). Roles of different phytochromes in Arabidopsis photomorphogenesis. Plant, Cell and Environment 20: 752-758.

WHITELAM, G. C., PATEL, S. and DEVLIN, P. F. (1998). Phytochromes and photomorphogenesis in Arabidopsis. Philos. Trans. R. Soc. Lond. B Biol. Sci. 353: 1445-53. YAMAGUCHI, S. and KAMIYA, Y. (2000). Gibberellin biosynthesis: its regulation by endogenous and environmental signals. Plant Cell Physiol 41: 251-257.

WU, Y., SANCHEZ, J. P., LOPEZ-MOLINA, L., HIMMELBACH, A., GRILL, E. and CHUA, N. H. (2003). The abi1-1 mutation blocks ABA signaling downstream of cADPR action. Plant J. 34: 307-315.

YAMAGUCHI, S. and KAMIYA, Y. (2001). Gibberellins and light-stimulated seed germination. J. Plant Growth Regul. 20: 369-376.

YAMAGUCHI, S., SMITH, M. W., BROWN, R. G., KAMIYA, Y. and SUN, T. (1998). Phytochrome regulation and differential expression of gibberellin 3beta-hydroxylase genes in germinating Arabidopsis seeds. Plant Cell 10: 2115-2126.

YAMAUCHI, Y., OGAWA, M., KUWAHARA, A., HANADA, A., KAMIYA, Y. and YAMAGUCH, S. (2004). Activation of gibberellin biosynthesis and response pathways by low temperature during imbibition of Arabidopsis thaliana seeds. Plant Cell 16: 367-378.

YANG, T., DAVIES, P. J. and REID, J. B. (1996). Genetic dissection of the relative roles of auxin and gibberellin in the regulation of stem elongation in intact Light-Crown Peas. Plant Physiol. 110: 1029-1034.

YANG, Y. Y., NAGATANI, A., ZHAO, Y. J., KANG, B. J., KENDRICK, R. E. and KAMIYA, $Y$. (1995). Effects of gibberellins on seed germination of phytochrome-deficient mutants of Arabidopsis thaliana. Plant Cell Physiol. 36: 1205-1211.

YANO, M., KATAYOSE, Y., ASHIKARI, M., YAMANOUCHI, U., MONNA, L., FUSE, T., BABA, T., YAMAMOTO, K., UMEHARA, Y., NAGAMURA, Y. and SASAKI, T. (2000). $H d 1$, a major photoperiod sensitivity quantitative trait locus in rice, is closely related to the Arabidopsis flowering time gene CONSTANS. Plant Cell 12: 24732484.

YANOVSKY, M. J. and KAY, S. A. (2002). Molecular basis of seasonal time measurement in Arabidopsis. Nature 419: 308-312.

YU, H., XU, Y., TAN, E. L. and KUMAR, P. P. (2002). AGAMOUS-LIKE24, a dosagedependent mediator of the flowering signals. Proc. Natl. Acad. Sci. USA 99: 1633616341.

ZHAO, Y., DAI, X., BLACKWELL, H. E., SCHREIBER, S. L. and CHORY, J. (2003). $S I R 1$, an upstream component in auxin signaling identified by chemical genetics. Science 301: 1107-1110.

ZEEVAART, J. A. D. (1984). Photoperiodic induction, the floral stimulus and flower promoting substances. In Light and the Flowering Process (ed. D. Vince-Prue, Thomas, B. Cockshull, K. E.), pp. 137-142. Academic, Orlando, FL. 